\title{
KORUNAN ALANLARIN ZAMANSAL DEĞIŞSIMININ LANDSAT UYDU GÖRÜNTÜLERİ İLE ANALIZİ: İĞNEADA LONGOZ ORMANLARI ÖRNEĞİ
}

\author{
Merve TOKER ${ }^{1}$, Filiz SUNAR ${ }^{2}$ \\ ${ }^{1}$ Orman ve Su işleri Bakanlığ \\ ${ }^{2}$ Prof. Dr. İstanbul Teknik Üniversitesi, İnşaat Fakültesi, Geomatik Mühendisliği Bölümü, 34469, Maslak, İstanbul, fsunar@itu.edu.tr
}

\begin{abstract}
ÖZET
Korunan alanlar sahip oldukları biyoçeşitlilik, çeşitli flora, fauna alanları ile koruma statüsü bulunan önemli kara ya da su kütlesine sahip ekosistemlerdir. Millî parklar da 2873 sayılı Millî Parklar Kanunu'na göre yönetilen koruma alanlarından biridir. İğneada Longoz Ormanları Millî Parkı sahip olduğu ve ülkemizde ender görünen ekosistemi ile Türkiye’nin 39. millî parkıdır. Yıldız (Istıranca) Dağları'ndan Karadeniz'e doğru akan derelerin klyı kumullarından dolayı denize ulaşamayıp birikmesi ve mevsime bağlı olarak sular altında kalmasıyla oluşan longoz ormanlart, Türkiye'nin sahip olduğu iklimsel özellikler nedeniyle ender görülen ekosistemlerdendir. Bu ender alanin sahip olduğu hassas dinamiklerin belirlenmesi ve korunması ekosisteminin sağllklı olarak devamlılığ için önemlidir. Korunan alanların planlaması koruma/kullanma dengesi gözetilerek çeşitli yöntemlerle yapılmaktadır. Planlama sırasında ya da planlama sonrası koruma alanlarını izleme-kapasite faaliyetleri için uzaktan algılama teknolojisinin kullanımı sürdürülebilirlik ve sağlıklı yönetimi için gereklidir. Bu çalışmada İğneada Longoz Ormanlarının sahip olduğu özelliklerin belirlenmesi ve milli park statüsü kazanması sonrasında olası değişimi ve yönünü incelemek amacıyla 1987 yllından 2007 yılına kadar 5 yıllık periyotlarda alınan Landsat TM görüntüleri ile milli park olarak ilan edilen 2007 yılından 2017 yılına kadar olan sürede 2 yıllık periyotlarda alınan Landsat TM ve OLI görüntüleri kullanılmıştır. Orman örtüsündeki değişimin saptanması amacıyla öncelikle Normalize Edilmiş Fark Bitki Örtüsü İndeksi (NDVI) uygulanmıştır. Daha sonra bu spektral dönüşümün kullanıldığı Landtrendr analizi ile İğneada Longoz Ormanlarının 1987 yılından 2017 yılına kadar değişimi ve değişimin yönü incelenmiştir.
\end{abstract}

Anahtar Sözcükler: korunan alanlar, Landsat, Landtrendr algoritması, zaman serileri, değişim saptama

\begin{abstract}
Protected areas are important land or water body ecosystems that have biodiversities, flora and fauna spaces. National Parks are the protected areas which are managed by 2873 number National Park Law. İgneada Floodplain Forests National Park is also one of the rare ecosystems in Turkey. The Floodplain forests are occurred, that the creeks flowing from Yildiz Mountains to the Black Sea cannot reach the sea due to the coastal dunes and they are flooded depending on the season. The floodplain forests one of the rare ecosystem due to climatic conditions that Turkey possesses. The identification and conservation of the sensitive dynamics of this rare area is important for healthy continuity. Planning the protected areas is carried out by several methods considering the protection / usage balance. Taking advantage of using satellite imagery during planning or using remote sensing technology for monitoring-capacity activities after planning, is essential for nature's sustainability and healthy management of protected areas. In this study national park, from 1987 to 2007, the change has been analyzed with Landsat time series quinquennialy. After declaration of national park in 2007, two years' interval up to 2017 Landsat TM and OLI images has been analyzed. Normalized Difference Vegetation Index (NDVI) was applied to determine the change in forest cover. This spectral transformation (NDVI) was arranged as input data in the Landtrendr algorithm and trend analysis performed at National Park. Through this analysis, the change and the direction of change at İgneada floodplain forests from 1987 to 2017 has been examined.
\end{abstract}

Keywords: protected areas, Landsat, Landtrendr algorithm, time series, change detection

\section{GİRIS}

İğneada Longoz (subasar) Ormanları millî parkı içinde barındırdığı farklı yaşam alanları ve Türkiye'nin sahip olduğu iklimsel özellikler nedeniyle ender görülen ekosistemlerdendir. Longoz ormanlarının asıl yaşam alanı tropikal bölgelerdir. Ülkemizde Karadeniz'de küçük bir bölgede de yer almakla birlikte ekosistem olarak en büyüğü İğneada Longoz Ormanlarıdır. Bu alan Bern Sözleşmesi'ne göre 'tehlike altında habitat tipi' olarak tanımlanan longoz ekosistemlerindendir. İğneada Longoz Ormanları, Yıldız Dağları'ndan Karadeniz'e akan göllerin önlerindeki kumullar nedeniyle ilkbaharda fazla şişerek suyun geriye doğru taşması ve araziyi kaplamasıyla oluşmuştur. Kış ve ilkbahar aylarında sularla kaplı, yaz aylarında ise kısmen suyu çekilen ormanlardan oluşmaktadır. Ayrıca birçok flora ve faunayı içinde barındıran, kuş göç yolları üzerinde yer alan, endemik türlere ev sahipliği yapan bu alan kıyı kumulları ile beraber sulak alanlara da sahiptir (Çevre ve Orman Bakanlığı ve Agrin Konsorsiyum, 2010).

$\mathrm{Bu}$ ender alanın sahip olduğu hassas dinamiklerin korunması ekosisteminin sürdürülebilirliği açısından önemli olduğundan bölgede meydana gelebilecek değişimlerin saptanması ve izlenmesi gerekmektedir. Günümüzde uydu 
teknolojileri kapsamında uzaktan algılama ve dijital görüntü işleme teknolojileri ile arazi örtüsündeki değişim alanlarının tespiti ve analizi etkin olarak yapılabilmektedir (Aslan vd., 2002).

Arazi örtüsündeki değişimlerin incelenmesinde kullanılan farklı analizlerden biri de trend analizidir. $\mathrm{Bu}$ amaca yönelik çeşitli trend analiz yöntemlerinin kullanıldığı çalışmalar literatürde mevcuttur. Bu çalışmalardan bir tanesi 1989-2013 yılları arasında Landsat uydu görüntülerini kullanarak Angola, Güney Afrika'da yer alan Miombo ormanlarında tarımsal işlemlerin sebep olduğu değişimleri ve yönlerini belirlemeyi amaçlayan trend analizidir. Çalışmada, Landsat uydu görüntülerinden zaman serileri oluşturulmuş ve bozulma indeksleri hesaplanmıştır. Trend analizi sonucunda orman örtüsünde yanarak bozulan alanların tarım arazisine dönüştürüldüğü saptanmış arazi çalışmaları ile de doğrulanmıştır (Schneibel vd., 2017).

Başka bir çalışmada; Amazon bölgesinde yer alan longoz ormanları örtüsündeki değişimin izlenmesi için 1984 ve 2009 yılları arasında alınan Landsat görüntüleri Landtrendr algoritması (Kennedy vd., 2010) ile incelenmiştir. Bu çalışmada longoz orman örtüsündeki gerilemenin insan baskısı ya da doğal koşullar sonucunda gerçekleştiğinin ortaya konulması amaçlanmıştır. İnsan baskısı sonucunda oluşan gerilemeyle zaman serilerinde ani değişimler gözlenirken doğal koşullar sonucu oluşan değiş̧imler ise daha yavaş gerçekleşmektedir (Fragal vd., 2016).

2010 yılında yayımlanan başka bir çalışmada ise trend analizi olarak Landtrendr yönteminin etkinliği test edilmiştir. $\mathrm{Bu}$ çalışmada Landtrendr algoritması ile Pasifik ormanlarında meydana gelen ani (yangın, toplu ağaç kesimi vb.) ve zamansal değişimlerin (böcek zararları vb.) tespitinin yapılabildiği gösterilmiştir (Kennedy vd., 2010).

Bu çalışmada, İğneada Longoz Ormanlarının sahip olduğu özellikleri ile millî park statüsü kazanması sonrasında olası değişimi ve yönü landtrendr yöntemi ile incelenmiştir. Uydu veri seti olarak 1987 yllından 2007 yllına kadar 5 yıllık periyotlarda alınan Landsat TM görüntüleri ile millî park olarak ilan edilen 2007 yılından 2017 yllına kadar olan sürede 2 yıllık periyotlarda alınan Landsat TM ve OLI görüntüleri kullanılmıştır.

\section{2. ÇALIŞMA ALANI VE KULLANILAN VERILER}

İğneada Longoz Ormanları Millî Parkı, Bulgaristan sınırı yakınında Karadeniz kıyısında ve Kırklareli ili, Demirköy ilçesi, İğneada beldesinde yer almaktadır. 27 derece doğu boylamı ile 41 derece kuzey enlemi arasında kalan alan, Batı Karadeniz iklimi etkisi altındadır. Şekil 1'de çalışma alanının konumu ve uydu görüntüsü verilmektedir.

Çalışma alanının tamamını oluşturan Millî Park; longoz orman ekosistemi, sulak alan ekosistemi, kıyı ekosistemi, kumul ekosistemi ve yaprak döken orman ekosistemlerinden oluşmaktadır. Alanda 9 tanesi endemik olmak üzere 12 tanesi nadir yayılış gösteren 21 tür flora çeşidi bulunmaktadır. Ayrıca Türkiye'de yaşayan 454 kuş türünün yarıya yakın kısmı İgneada Longoz Ormanları Millî Parkı'nda görülebilmektedir. Sulak alan ekosistemleri birçok göçmen kuşun uğrak yeridir (Çevre ve Orman Bakanlığı ve Agrin Konsorsiyum, 2010).
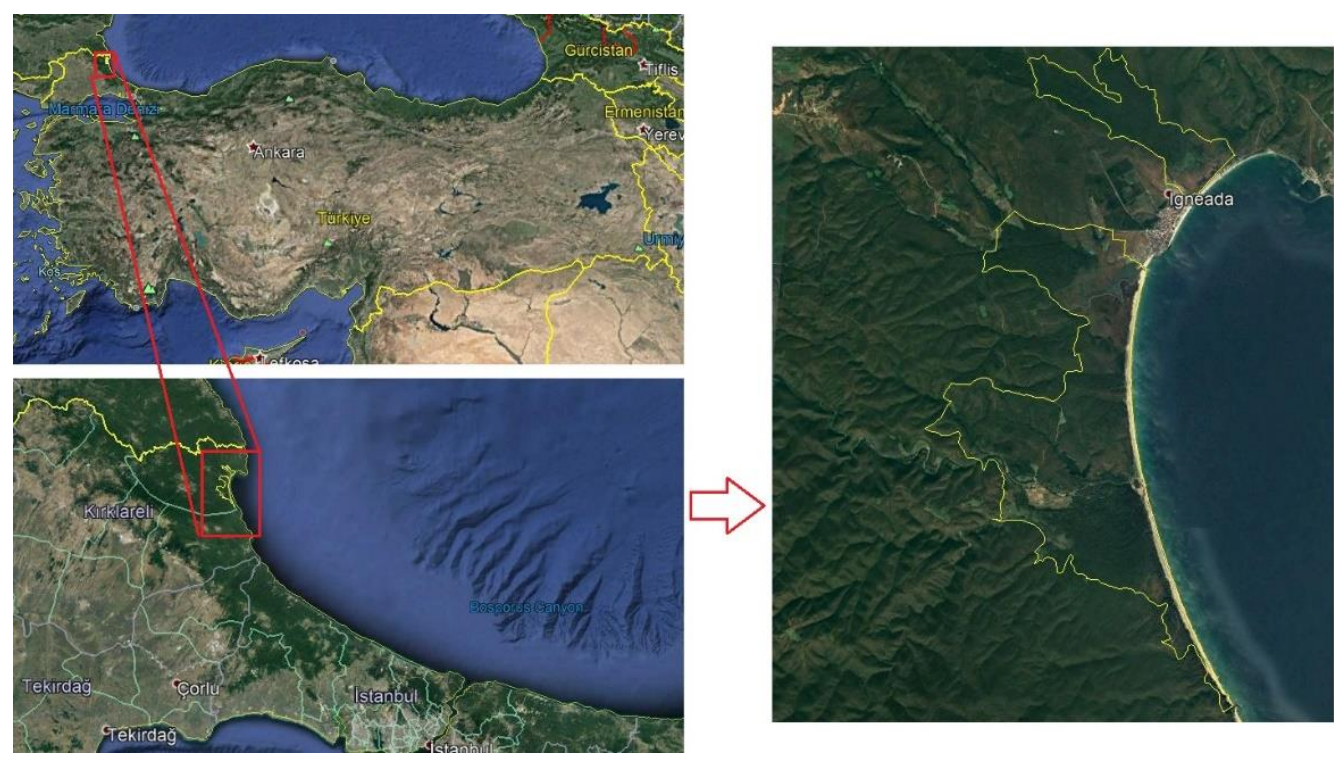

Şekil 1: Çalışma alanının konumu ve uydu görüntüsü. 
Uzaktan algılamanın ilk uygulama alanı askerî amaca yöneliktir ancak zaman ve teknolojinin ilerlemesine paralel olarak daha sonraları sivil amaçlara yönelik olarak kullanılmaya başlanmıştır. Landsat uydu sistemi de 1970`li yıllarda arazi örtüsü hakkında detayların toplanması ve haritalandırılması için oluşturulmuştur (Sunar vd., 2011). Bu çalışmada 1987 yılından 2007 yılına kadar 5 yıllık aralıklarla ve 2007 yılından 2017 yılına kadar 2 yıllık aralıklarla alınan toplam 10 Landsat uydu görüntüsü kullanılmıştır. Çizelge 1'de kullanılan uydu verilerinin genel karakteristikleri verilmiştir.

Çizelge 1. Çalışmada kullanılan Landsat uydu verilerinin teknik özellikleri.

\begin{tabular}{|c|c|c|c|c|c|}
\hline Uydu & Tarih & & ral & $\begin{array}{c}\text { Mekansal } \\
\text { çözünürlük } \\
\text { (m) }\end{array}$ & $\begin{array}{c}\text { Zamansal } \\
\text { çözünürlük } \\
\text { (gün) }\end{array}$ \\
\hline \multirow{7}{*}{ Landsat TM } & 15.08.1987 & Band1 & $0.45-0.52$ & \multirow{7}{*}{30} & \multirow{7}{*}{16} \\
\hline & 28.08.1992 & Band2 & $0.52-0.60$ & & \\
\hline & 25.07.1997 & Band3 & $0.63-0.69$ & & \\
\hline & 14.06.2002 & Band4 & $0.76-0.90$ & & \\
\hline & 05.07.2007 & Band5 & $1.55-1.75$ & & \\
\hline & 24.06.2009 & Band6 & $10.40-12.50$ & & \\
\hline & 17.08.2011 & Band7 & $2.08-2.35$ & & \\
\hline \multirow{11}{*}{ Landsat OLI } & \multirow{11}{*}{$\begin{array}{l}06.08 .2013 \\
12.08 .2015 \\
01.08 .2017\end{array}$} & Band1 & $0.435-0.451$ & \multirow{11}{*}{30} & \multirow{11}{*}{16} \\
\hline & & Band2 & $0.452-0.512$ & & \\
\hline & & Band3 & $0.533-0.590$ & & \\
\hline & & Band4 & $0.636-0.673$ & & \\
\hline & & Band5 & $0.851-0.879$ & & \\
\hline & & Band6 & $1.566-1.651$ & & \\
\hline & & Band7 & $2.107-2.294$ & & \\
\hline & & Band8 & $0.503-0.676$ & & \\
\hline & & Band9 & $1.363-1.384$ & & \\
\hline & & Band10 & $10.60-11.19$ & & \\
\hline & & Band11 & $11.50-12.51$ & & \\
\hline
\end{tabular}

\section{YÖNTEM}

$\mathrm{Bu}$ çalışmada orman örtüsündeki değişimin saptanması amacıyla öncelikle Normalize Edilmiş Fark Bitki Örtüsü İndeksi (NDVI) uygulanmış ve daha sonra bu spektral dönüşümün kullanıldığı Landtrendr analizi ile İğneada Longoz Ormanlarının 1987 yılından 2017 yılına kadar değişimi ve değişimin yönü incelenmiştir.

NDVI (Normalize Edilmiş Fark Bitki Örtüsü İndeksi) bitki örtüsü indeksleri arasında yaygın olarak kullanılan oransal bir yöntemdir ve NDVI = (Yakın kızılötesi bant - Kırmızı bant) / (Yakın kızılötesi bant + Kırmızı bant) şeklinde matematiksel olarak ifade edilir. Eşitliğin yakın kızılötesi ve kırmızı bantlarla normalize edilmesi ile farklı güneş ve bakış açıları etkileri giderilmektedir. NDVI indeks değerleri -1 ile 1 aralığındadır. Sağlıklı bir bitki örtüsü alanının indeks değeri +1 değerine doğru yaklaşırken bitki örtüsü taşımayan kayalık alanlar ya da kıraç topraklarda indeks değeri 0 ile -1 aralığında yer alır (Sunar vd., 2011).

Landtrendr algoritması; Landsat uydu görüntüleri kullanılarak arazi örtüsündeki bozulma ve iyileşmeleri piksellerin zamansal değişiminden yola çıkarak zaman serileri ile ortaya koyan bir analiz yöntemidir (Kennedy vd., 2010). Algoritmanın uygulanmasında öncelikle uydu görüntülerinden NDVI indeksleri hesaplanarak normalize edilir. Daha sonra seçilen bölgenin tüm yıllara ait piksel değerleri ile zaman serisi oluşturulur ve regresyon analizinden önce aykırı ölçüler testi yapılır. Aykırı ölçülerden temizlenen zaman serisine lineer trend modeli uygulanır. Analiz sonuçlarına bakılarak modelden sapmanın en fazla olduğu noktadan seri ikiye ayrılır ve her iki zaman serisi için yeniden lineer regresyon modeli uygulanır. Bu işleme maksimum segmentasyon sayısına ulaşıncaya kadar devam edilir. Oluşturulan modeller arasından seçim yapılırken her model için F-test büyüklüğü ve buna karşılık olasılık değerleri (p-değeri) hesaplanır. P olasılık değerlerine bakılarak model seçimine karar verilir (Kayıkçı ve Sopacı, 2015). Yöntemin akış şeması Şekil 2'de verilmektedir. 


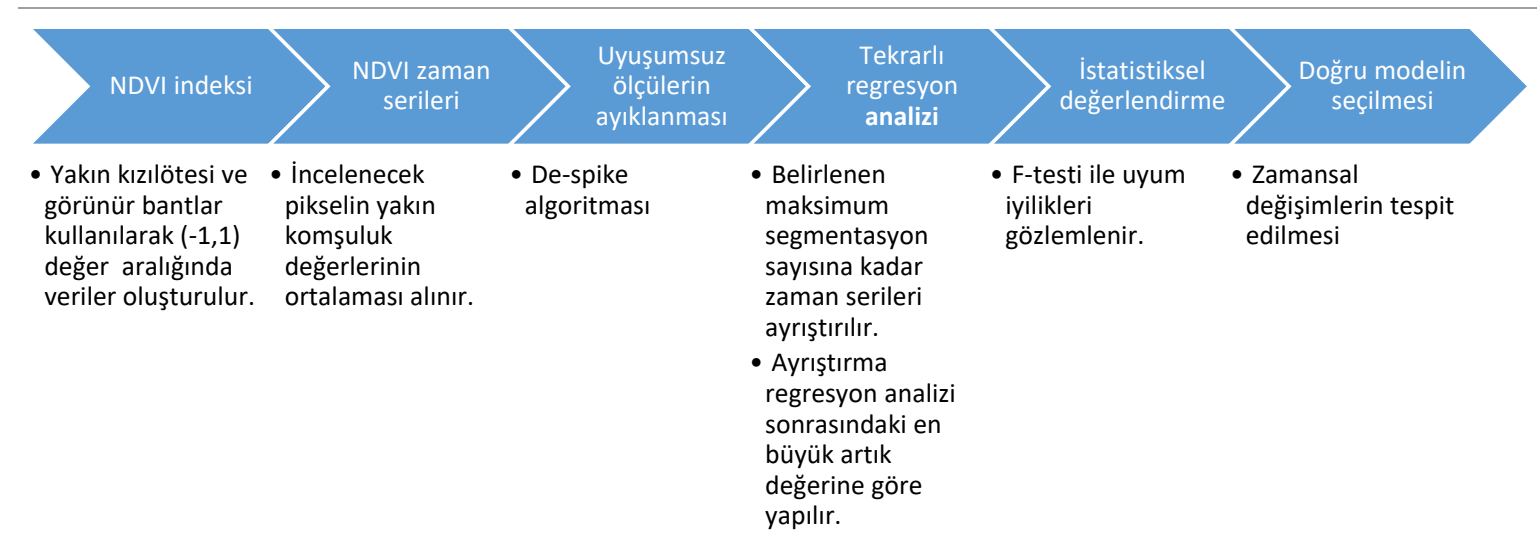

Şekil 2: Landtrendr algoritmasının akış şeması.

\section{UYGULAMA}

Bu çalışmada Longoz ormanlarının değişimini ve yönünü analiz edebilmek için Landsat uydu görüntülerine Landtrendr analizi uygulanmıştır. Alınan görüntülerde mevsimsel etkilerinin olmaması için görüntülerin yakın mevsim ve tarihlerde alınmış olmasına dikkat edilmiş, vejetasyon dönemi olarak haziran, temmuz ve ağustos aylarına ait görüntüler kullanılmıştır.

İlk adım olarak görüntüler alana uygun olarak kesilerek geometrik düzeltmeleri yapılmış ve NDVI indeksi ile $(-1,1)$ aralığına getirilerek normalize edilmiştir. Daha sonra değişimin inceleneceği test bölgeleri belirlenmiş ve zaman serileri oluşturulmuştur. Regresyon analizlerinden önce aykırı değerler de-spike algoritması ile giderilmiştir. Aykırı değerlerden temizlenen zaman serilerine tekrarlı regresyon analizleri yapılmıştır. Her regresyon sonrasında veri en büyük artık değerden ikiye bölünmüştür. Bölünen zaman serileri için yeniden regresyon analizleri yapılmıştır. Bu işleme tekrarlı olarak maksimum segmentasyon değerine ulaşıncaya kadar devam edilmiştir. Oluşturulan birçok regresyon modelleri için $\mathrm{F}$ dağılımındaki p olasılık değerleri hesaplanarak modellerin veriye uygunlukları karşılaştırılmıştır. Elde edilen test sonuçları değerlendirilerek zamansal değişimler ve yönleri (örn., gerileme, iyileşme vb.) saptanmıştır.

\subsection{Test bölgelerinin seçimi}

Test bölgeleri seçiminde değişim olabileceği düşünülen alanlar göz önüne alınmıştır ( Şekil 3). Şekilde kırmızı renk ile gösterilen 3 test bölgesi alanın kuzeyindeki longoz ormanları, Mert Gölü bölgesindeki sulak alan çevresi ve alanda yer alan karışık orman mesçeresine karşılık gelmektedir. 


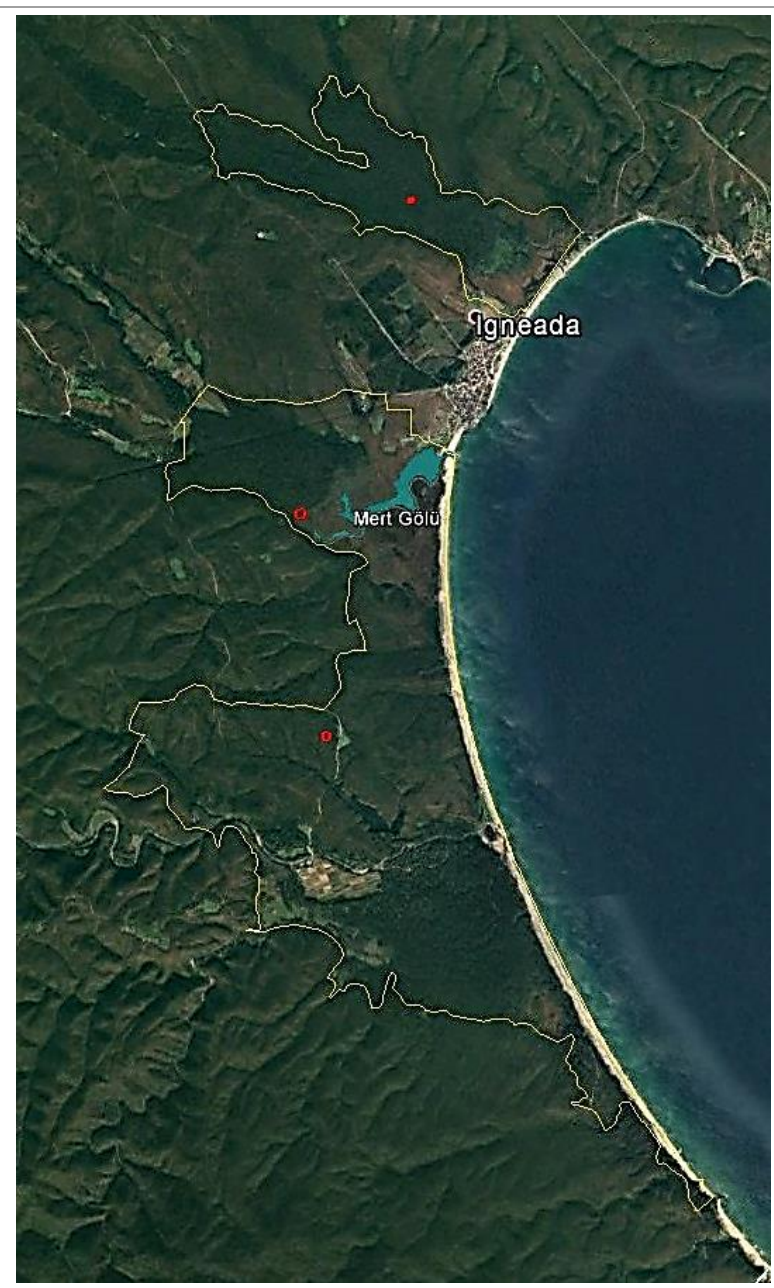

Şekil 3: Çalışmada göz önüne alınan test bölgeleri.

\subsection{Landtrendr Algoritması uygulaması}

İlk bölge olarak alanın kuzeyinde bulunan longoz ormanı ele alınmış ve bölgeye ait zamansal uydu görüntüleri ile regresyon modelleri Şekil 4ve Şekil 5'te gösterilmiştir. Şekil 5(a)' da görüldüğü gibi 2011 yılındaki değișim, ani bir düşüş sonrasında yine aynı hızla yükselerek eski halini aldığından de-spike algoritması ile aykırı değer olarak saptanmıştır. İlk modelde sadece yukarı yönlü bir trend görülmektedir (Şekil 5(b)). İkinci modelde ise trend 2002 yılına kadar bir eğim değerine, 2007 yılından sonra başka bir eğim değerine sahiptir. Üçüncü model 1997 yılındaki değişimi de saptamıştır. 1997 yılında bu bölgede hem yaşanan kış şartları hem de ağaç kesiminden dolayı eksi yönde değişim yaşanmıştır (Türkiye Büyük Millet Meclisi 2004). Bu dönemden sonra ağaç kesimleri durdurulmuş ve 2002 yılından sonra hızlı bir toparlanma saptanmıştır. Grafikte gösterilen bu değişimler yersel ve yardımcı veriler ile uyuşum göstermektedir. Ayrıca son model, hem 1997 yılında kaynaklanan ağaç kesilmelerini hem de 2002 yılından sonraki vejetasyondaki toparlanmayı daha doğru bir şekilde saptamıştır. F testi olasılık değerlerine bakıldığında da en uygun model son modeldir.

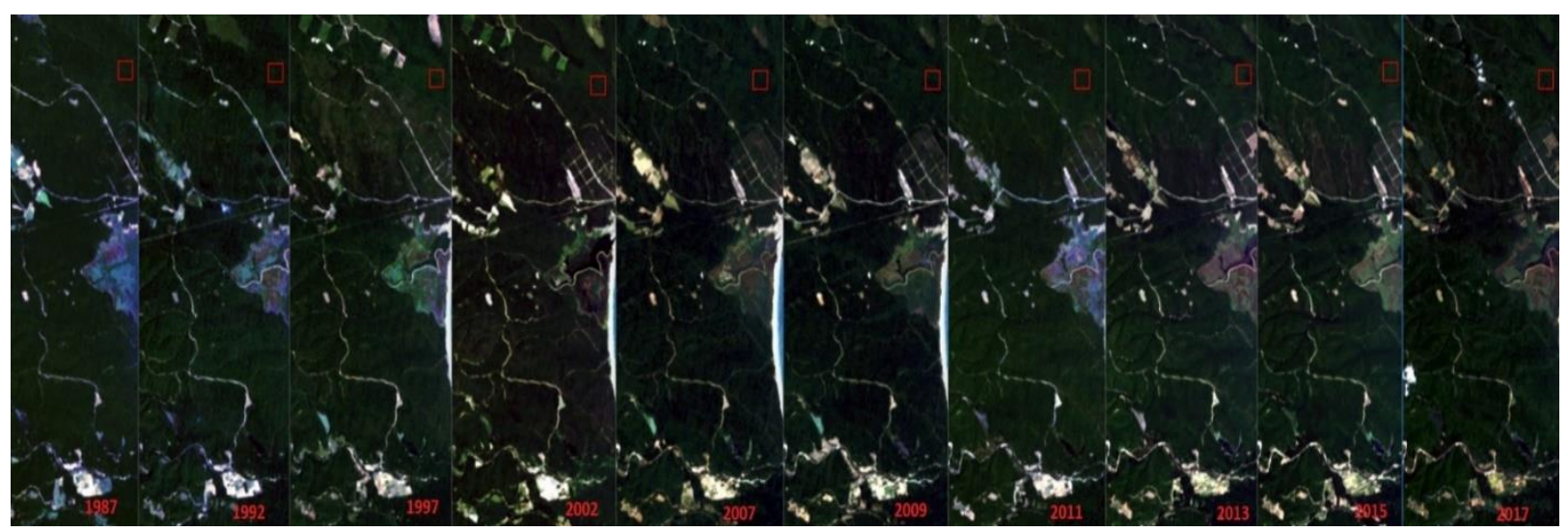


Şekil 4: Korunan alanın kuzey bölümündeki longoz ormanı test bölgesinin zamansal uydu görüntüleri.
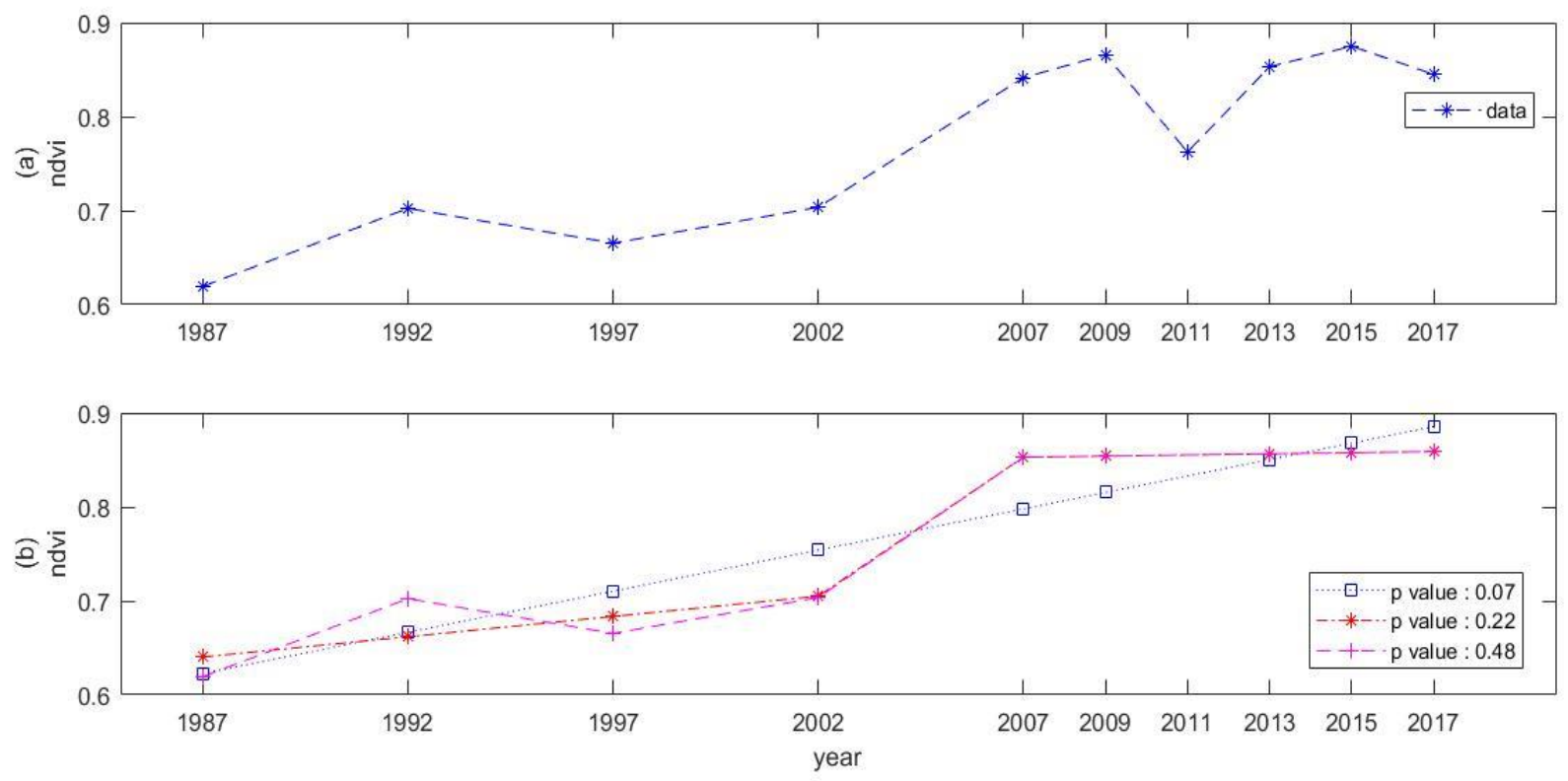

Şekil 5: Korunan alanın kuzey bölümündeki longoz ormanı test bölgesi landtrendr algoritması sonuçları

(a) Ham hâldeki zaman serisi (b) F testi sonucu olasılık değerlerine (p value) göre regresyon analizleri.

Şekil 6'da korunan alanın orta bölümünde yer alan karışık orman mesçeresine ait test bölgesine ait zamansal uydu görüntüleri gösterilmektedir. Şekil 7'de ise test bölgesine ait landtrendr algoritması sonuçları verilmektedir. İlk model düzenli artan bir trend eğiliminde olmakla beraber 1997 yılındaki düşüşü göz ardı etmektedir. Son modelde hem 1997 yılındaki düşüş gözlemlenmiş hem de 2011 yılındaki değişim de-spike algoritması ile aykırı değer olarak saptanmıştır.

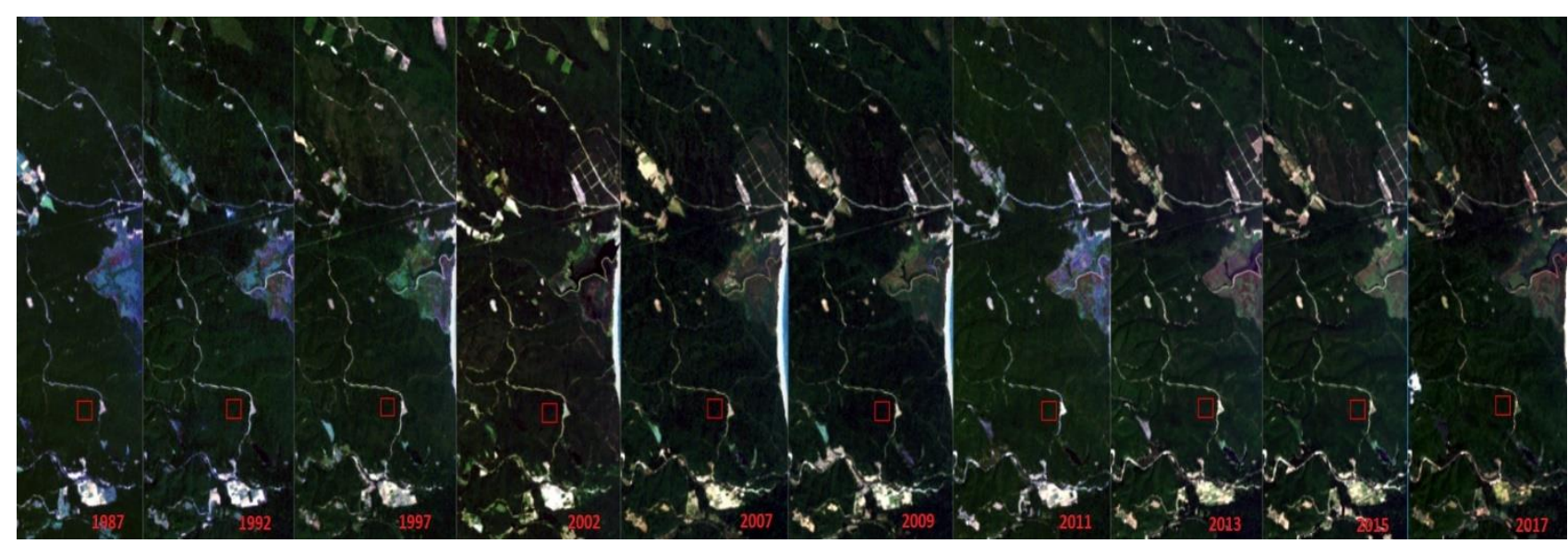

Şekil 6: Korunan alanın orta bölümünde yer alan karışık orman alanına ait test bölgesinin zamansal uydu görüntüleri. 

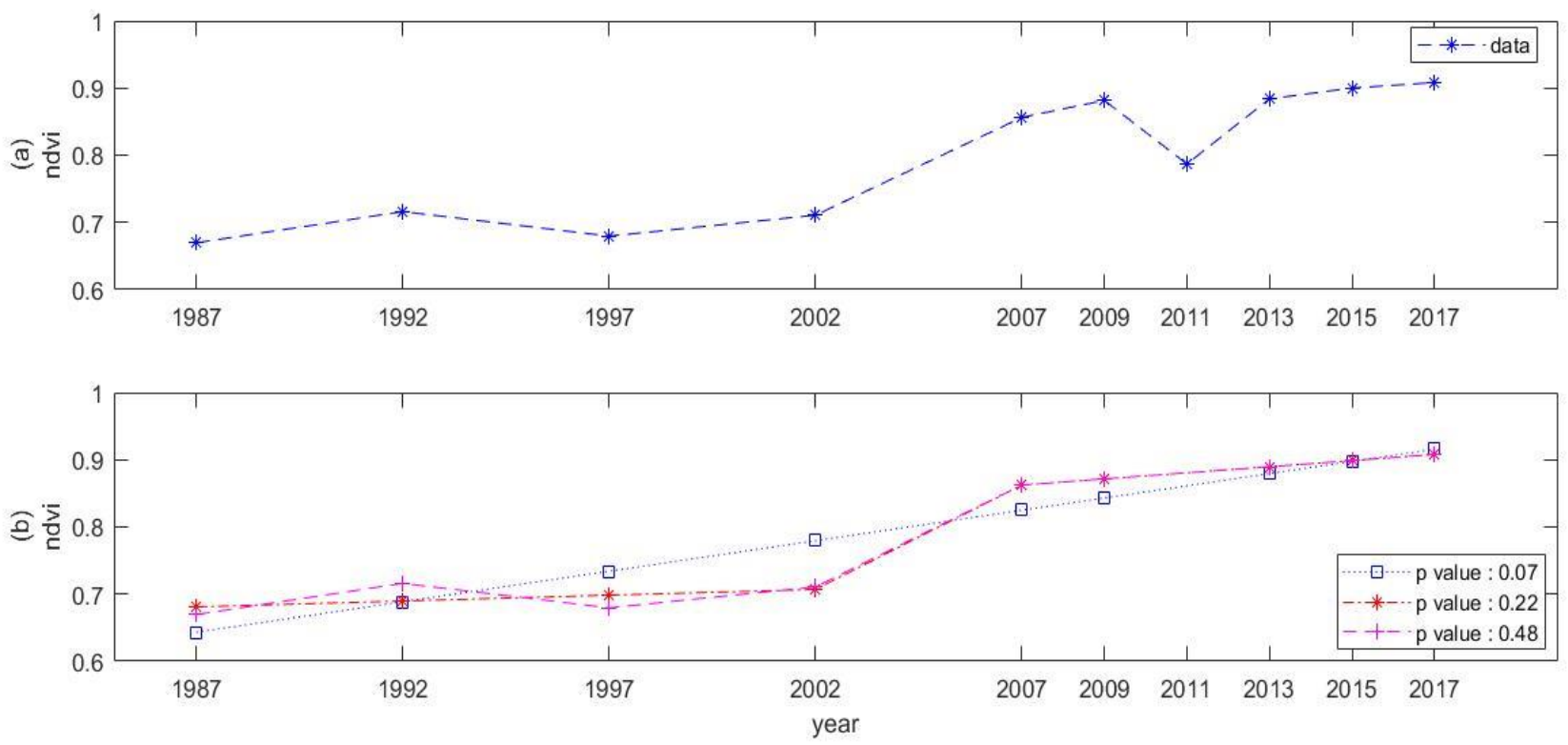

Şekil 7: Korunan alanın orta bölümünde yer alan karışık orman alanına ait test bölgesi landtrendr algoritması

sonuçları (a) Ham hâldeki zaman serisi (b) F testi sonucu olasılık değerlerine ( $p$ value) göre regresyon analizleri.

Son test bölgesi olan Mert Gölü yakınında yer alan bölgeye ait zamansal uydu görüntüleri Şekil 8'de gösterilmektedir. Mert Gölü, korunan alanı ikiye bölen İğneada beldesine çok yakın bir konumdadır. Şekil 9'da ise Mert Gölü yakınındaki test bölgesine ait landtrendr algoritması sonuçları verilmektedir. Şekil 9(b)'de gösterilen grafikte yer alan ilk modelde sürekli artan bir trend gözükmektedir. İkinci modelde 2002 yılına kadar sert bir düşüş sonrasında ise bir toparlanma görülmektedir. İğneada beldesinden Mert Gölü'ne bırakılan kanalizasyon atıklarının yol açtığı düşüş, 2005 yılından itibaren kullanılan arıtma sisteminin etkisiyle ekosistemin kendini toparlamaya başladığını göstermektedir (World Wildlife Foundation ve Çevre ve Orman Bakanlığ 2007).

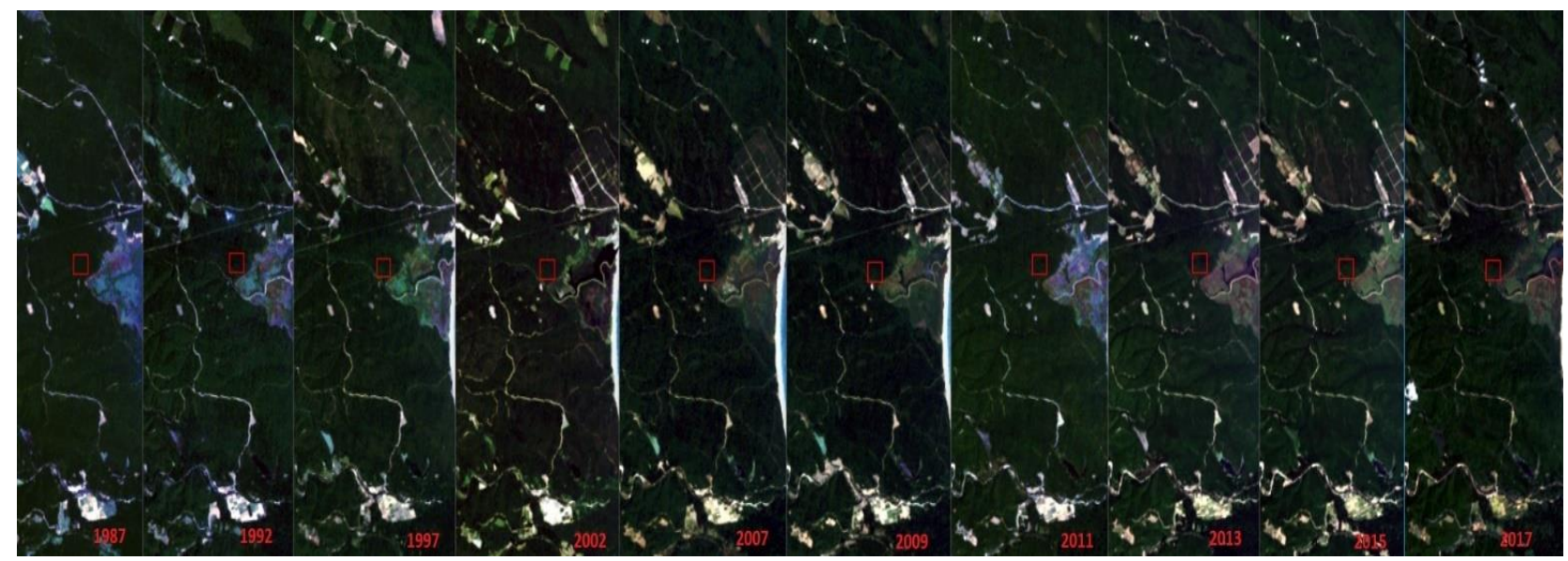

Şekil 8: Mert Gölü yakınında yer alan test bölgesinin zamansal uydu görüntüleri. 

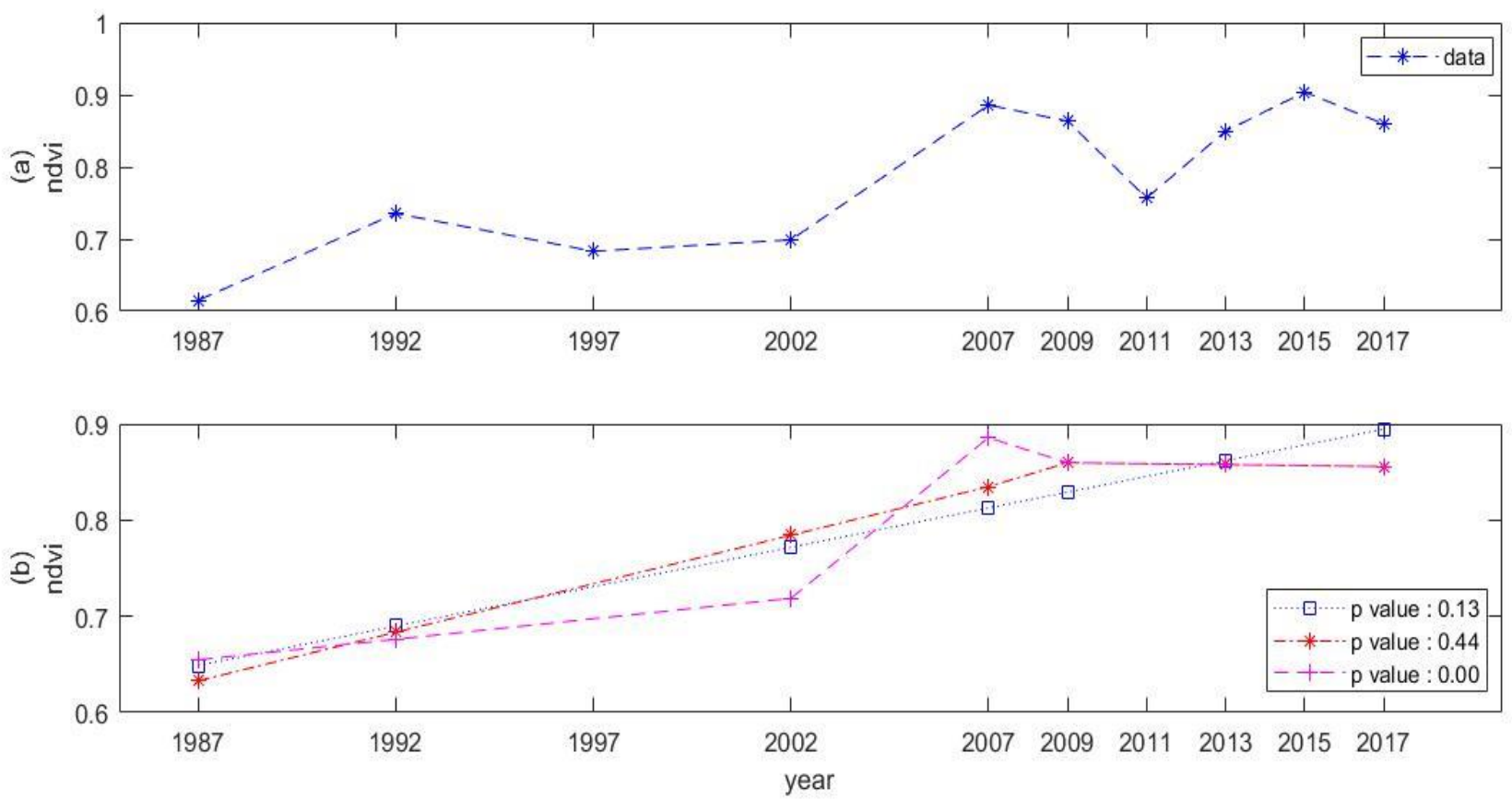

Şekil 9: Mert Gölü yakınında yer alan test bölgesi landtrendr algoritması sonuçları (a) Ham hâldeki zaman serisi

(b) F testi sonucu olasılık değerlerine ( $p$ value) göre regresyon analizleri.

\section{SONUÇ}

Bu çalışmada Longoz ormanlarının değişimini ve yönünü analiz edebilmek için çok-zamanlı Landsat uydu görüntülerine Landtrendr analizi uygulanmış ve elde edilen model sonuçlarının yersel verilerle uyumlu olduğu saptanmıştır. Landtrendr yöntemine göre 1992 - 1997 yılları arasında orta bölümünde yer alan karışık orman alanlarındaki düşüşler bu yıllar arası zorlu geçen kış şartları ile devrilen ağaçlar ve yine aynı alanda Orman İşletme Müdürlüğü tarafından kesilen ağaçlar neticesinde yaşanmıştır. Sulak alan bölgesindeki düşüşlerin nedeni ise Mert Gölü’ne bırakılan kanalizasyon atıklarından dolayıdır. Koruma alanı statüsü yıllar içinde sürekli değişen, zaman zaman nükleer zaman zaman termik santral yapılması tehlikesi ile karşı karşıya kalan benzer hassas ekosistemlerin dinamiklerinin korunması, izlenmesi, sürdürülebilirliğinin sağlanması açısından çok önemlidir. Algoritmanın daha fazla sayıda uydu görüntüsü ve farklı doğrulama yöntemleri kullanılarak ülkemizdeki mevcut korunan alanlar için etkin bir izleme ve yönetim aracı olarak kullanılabilirliği bu çalışmada gösterilmiştir.

\section{KAYNAKLAR}

Aslan, Z., Skidmore E., Feoli, E., Maktav, D., Erol, H., Erbek, F.S., Okçu, D., Söğüt, A., Giacomich,P., Mauro S. ve Mighozzi, K., 2002. The Use of Conventional Data and Remote Sensing for Classification of Erosion and Land Degradation. Agro Environ, Konferans yayını: 1-12.

Çevre ve Orman Bakanlı̆̆ı, Agrin Konsorsiyum, 2010. Yıldız Dağları Biyosfer Projesi, Çevre ve Orman Bakanlığı. Ankara, 154 sayfa.

Fragal, E.H., Silva, T.S.F. ve Novo, E.M.L.M., 2016. Reconstructing Historical Forest Cover Change in the Lower Amazon Floodplains Using the LandTrendr Algorithm. Acta Amazonica.46: 13-24.

Kayıķ̧ı, E.T., ve Sopacı, E., 2015. Testing the Normality of the Residuals of Surface Temperature Data at VLBI/GPS Co-located Sites by Goodness of Fit Tests. Arabian Journal of Geosciences, 8: 10119-10134.

Kennedy, R.E., Yang, Z. ve Cohen, W.B., 2010. Detecting Trends in Forest Disturbance and Recovery Using Landsat Time Series:1.Landtrendr-Temporal Segmentation Algorithms. Remote Sensing of Environment, 2897: 2910 $-2010$. 
M. Toker ve F. Sunar: Korunan Alanların Z. D.nin Landsat U. G. İle Analizi: İğneada Longoz Ormanları Örneği

Schneibel, A., Frantz, D., Röder, A., Stellmes, M., Fischer K. ve Hill, J., 2017. Using Annual Landsat Time Series for the Detection of Dry Forest Degredation Processes in South-Central Angola. Remote Sensing, 9, 905: 1 - 14.

Sunar, F., Özkan, C. ve Osmanoğlu, B., 2011. Uzaktan Algllama, 1.basım, Anadolu Üniversitesi Web-Ofset, Eskişehir, 210 sayfa.

Türkiye Büyük Millet Meclisi , 27.10.2004. Tutanak Dergisi, Ankara, 284 sayfa.

World Wildlife Foundation ve Çevre ve Orman Bakanlı̆̆ı, 2007. Ĭğneada Koruma Alanı Planlama ve Yönetimi, Çevre ve Orman Bakanlığı. Ankara, 230 sayfa. 